NASA Technical Memorandum 100226

\title{
Flight Propulsion Control Integration for V/STOL Aircraft
}

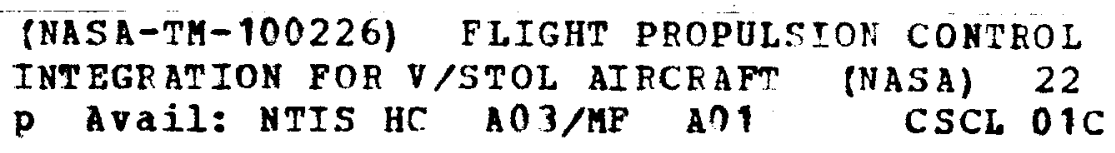

James R. Mihaloew

Lewis Research Center

Cleveland, Ohio

Prepared for the International Powered Lift Conference sponsored by the Society of Automotive Engineers Santa Clara, California, December 7-10, 1987 


\title{
FLIGHT PROPULSION CONTROL INTEGRATION FOR V/STOL AIRCRAFT
}

\author{
James R. Mihaloew \\ National Aeronautics and Space Administration \\ Lewis Research Center \\ Cleveland, Ohio 44135
}

\begin{abstract}
The goal of the propulsion community is to have the enabling propulsion technologies in place to permit a low risk decision regarding the initiation of a research STOVL supersonic attack/fighter aircraft in the mid-1990's.

This technology will effectively integrate, enhance, and extend the supersonic cruise, STOVL, and fighter/attack programs to enable U.S. industry to develop a revolutionary supersonic short takeoff/vertical landing fighter/attack aircraft in the post-ATF period. The rationale, methods, and criteria used in developing a joint NASA Lewis and NASA Ames research program to develop the technology element for integrated flight-propulsion control through integrated methodologies is presented. This program, the Supersonic STOVL Integrated Flight-Propulsion Controls Program, is part of the overall NASA Lewis Supersonic STOVL Propulsion Technology Program. It uses an integrated approach to an integrated program to achieve integrated flight-propulsion control technology.
\end{abstract}

During the 1970's many innovative aircraft configurations were proposed as viable solutions to $\mathrm{V} / \mathrm{STOL}$ mission requirements. High-performance propulsion systems were conceived for these V/STOL aircraft. These propulsive $1 \mathrm{ift}$ concepts consisted of remote lift fans driven by rigid shafts or ducted high energy gas, lift/cruise nacelles, thrust vectoring swivel nozzles, remote augmentors, and reaction control/compressor bleed systems. The primary problem in developing propulsion system concepts is to design systems which provide the required aircraft handling qualities in powered-lift modes without robbing the powerplant of its ability to perform safely and economically. During low speed operations V/STOL aircraft are not only dependent upon these propulsion systems for lift, but also for the forces and moments needed for flight path and attitude control. Thus, highly coordinated flight and propulsion control systems are critical to the success of these advanced V/STOL aircraft.

The need for new, integrated V/STOL aircraft and propulsion control concepts has developed at the same time that great changes are taking place in the field of aerospace controls. The microprocessor revolution is producing very low cost, high-speed computation which will make many control system implementation concepts feasible that just a few years ago would have been economically impossible and physically impractical due to control function complexity. This technology development has dramatically improved computer reliability and functional capability and will have a profound impact on all future engine and aircraft designs. However, the main problem in flight-propulsion integration from a reliability viewpoint is that propulsion control reliability must reach flight control reliability levels.

Historically, aircraft design has been based on the philosophy that flight and propulsion controls can be designed independently. This philosophy 
assumed that the pilot could effectively integrate these subsystems by his control inputs. Future mission requirements, especially for powered-lift aircraft, demand improved operational capabilities so that the pilot's attention can no longer be directed to integrating the flight and propulsion control subsystems. He must instead direct his attention to higher levels of concern as demanded by his mission and monitor the progress of his mission through the imposed threats. The integration of the flight and propulsion subsystems will allow the pilot greater attention to those higher levels of concern by supplanting a good part of the pilot's integration function and thereby reduce pilot workload.

Functional subsystem integration holds not only the promise of achieving reduced pilot workload but also of improving the performance of the total flight system. Integration will coordinate various system functions associated with airframe, inlet, engine, nozzle, attitude control, and other thrust effectors. The aircraft control actions will be coordinated in a global sense to optimize operation in all flight modes. In the process, system efficiency should increase which should result in smaller propulsion systems with a subsequent lower V/STOL penalty.

Classical design methods and approaches are generally inadequate to attack integrated control since they do not account for, in a systematic manner, the inherent cross-couplings of an integrated system. It will obviousiy be necessary to treat the entire aircraft as one dynamic system. Therefore, advanced design methods within the context of an integrated control design methodology must be employed to achieve this high level of aircraft systems integration and the degree of coordination required between airframe and engine control designers will have to be increased well beyond that of conventional programs.

This paper will present the rationale, methods, and criteria in developing a joint NASA Lewis and Ames research program to develop the technology for integrated flight-propulsion control through integrated methodologies. This program, the Supersonic STOVL Integrated Flight-Propulsion Controls Program, is part of the overall NASA Lewis Supersonic STOVL Propulsion Technology Program. It uses an integrated program approach to achieve integrated flightpropulsion control technology.

HISTORICAL PERSPECTIVE - Several past and continuing research programs have addressed integrated flight-propulsion control. The first of these, the Integrated Propulsion Control System (IPCS) (ref. 1) begun in the late 1960's, was a flight test program to integrate the inlet and engine control systems for inlet shock and automatic restart control. An F-111 with an airframe-mounted digital computer was used to test a full-authority control on the left inlet and engine.

Soon after, the Quiet Clean Short-haul Experimental Engine (QCSEE) was evaluated in conjunction with a piloted simulator investigation of engine failure compensation for powered-lift STOL aircraft (refs. 2 and 3 ). The study pointed up the requirement for an integrated aircraft propulsion system approach for high response, close-coupled powered lift systems.

In-depth studies of flight-propulsion control integration were conducted by the Air Force in the mid-1970's. The studies included the Flight 
Propulsion Control Coupling (FPCC) program, the dynamic interaction investigation (refs. 4 and 5) and were followed by the Control Configured Propulsion (CCP) design criteria definition (ref. 6). Other studies by NASA included the Cooperative Airframe/Propulsion /Control System program (ref. 7) and the Integrated Research Aircraft Technology (INTERACT) project (ref. 8). The former demonstrated digitally integrated inlet/autopilot/autothrottle control on a YF-12. INTERACT was a further flight/propulsion integration program which also demonstrated significant benefits of control integration.

In the late 1970's, NASA pursued a control concept definition program to investigate the basic changes in flight and propulsion control design rationale, criteria and methodology needed to take maximum advantage of advances in control technology. The V/STOL Controls Analys is Program, conducted by NASA Lewis, was initiated in 1979 with the realization that basic and profound changes in flight and propulsion control design were needed to take maximum advantage of advanced control technology for the next generation, both subsonic and supersonic, V/STOL aircraft. The initial step of this control concept investigation was to review the V/STOL propulsion control technology requirements. Emerging from the myriad of viable V/STOL aircraft configurations were many generic propulsion components that must be controlled and integrated with the flight control laws. As a result, many challenging control issues were found that needed to be resolved.

The V/STOL Controls Analysis Program (refs. 9 and 10) provided an initial step toward the development of the methodology and technology base required for the integration of V/STOL aircraft-propulsion control systems. The program consisted of a technical effort divided into two phases to initiate the development of the technology base required for V/STOL aircraft prototype development. Phase I pursued formulation of a long range plan to establish the technology base for the design of V/STOL integrated aircraft-propulsion control, established preliminary V/STOL propulsion control requirements, and developed mathematical modeling and simulation techniques applicable to the design of V/STOL integrated aircraft-propulsion controls. A technology plan from one of the two studies, as depicted in figure 1, was one of the primary outputs of this phase. Phase II efforts addressed integration of aircraft requirements into V/STOL propulsion control technology development, development of mathematical modeling and simulation techniques for integration of the flight and propulsion control of various V/STOL thrust effectors, development of propulsion control design methodology and logic capable of modulating the various V/STOL thrust effectors within safe propulsion system limits, and the assessment of the ability of V/STOL thrust effectors to meet aircraft control requirements. The research represented the completion of 2 years of a formulated 6 year technology plan producing results applicable to the integration of flight and propulsion control systems.

As a continuation of the concept of integrated fight-propulsion control integration, the Air Force Wright Aeronautical Laboratory (AFWAL) sponsored a program wherein teams of aircraft, engine and controls specialists conducted integrated control design efforts aimed at establishing a control design methodology. The Design Methods for Integrated Control Systems (DMICS) was a dual-award effort (refs. 10 and 11). General Dynamics, Pratt \& Whitney Aircraft, Honeywell Systems Research Center, and Hamilton-Standard constituted one team while Northrop Corporation, General Electric Aircraft Engine Group, and Systems Control Technology formed the other. Two design methodologies 
were produced, one involving a global approach and the other, a partitioned approach. Specific outputs of this study included a comprehensive aircraft/ propulsion/integrated control simulation, mathematical algorithms for the design of integrated control laws, and evaluation of the effectiveness of the integrated control design, and preliminary assessments of integrated control impact on control architecture.

The DMICS program consisted of four phases as shown in figure 2. Phase I was directed at the development of integrated control system design requirements. Phase II involved the development of a simulation to be used as a tool in the design of integrated control logic. Phase III consisted of two primary tasks. The first involved the design of the integrated control logic and the second was an evaluation of how an integrated flight-propulsion control system could be effectively implemented. Phase IV involved the evaluation of the integrated control logic on a simulation basis. The methodology developed under DMICS has yet to be applied to an actual design case and demonstrated experimentally.

The NASA Ames/Dryden Highly Integrated Digital Electronic Control (HIDEC) program, a NASA sponsored program to develop and flight demonstrate integrated flight propulsion control modes on a McDonnell Douglas F-15 Eagle aircraft, began in 1983. Two high-payoff integrated modes were developed (ref. 13). The Trajectory Control/Energy Management mode demonstrated not only increased weapon system effectiveness through fuel savings and increased intercept ranges, but also served as a stepping stone to other control applications such as terrain following-terrain avoidance and automated air combat. The Variable Operating Line mode demonstrated benefits of increased thrust without increasing engine size and weight. The flight control and engine modifications made to implement these modes will also support future NASA programs for optimizing flight propulsion control interactions.

Most integrated control done up to this point has involved only specialized purposes such as weapons control and in the up-and-away flight regime. With the exception of DMICS, no generalized approach has been taken in the design of integrated flight-propulsion control on a global basis. Further, with the exception of the V/STOL Controls Analysis program, virtually no integrated control concepts have been applied or developed for powered-lift aircraft. Powered-lift aircraft differ from wing-borne flight only in terminal operation modes, that is, short-takeoff, transition to hover, hover, and vertical landing. Transition is generally without complication of mission requirements or duress. However, this mode requires considerable coordination and pilot integration and thus, high workload. Propulsion requirements in this flight phase can also determine propulsion system size. From these considerations, the Supersonic STOVL Integrated Flight-Propulsion Control Program has evolved. The approach to formulate the program is basically the continuation and extension of the V/STOL Propulsion Controls Analysis program using the integrated flight-propulsion controls methodologies developed under DMICS. 


\section{INTEGRATED CONTROL}

\section{Philosophical Foundations}

Before launching into a discussion of integrated control, perhaps a definition of the subject would be in order to set the stage. The word "integrate" in its broadest form means to form, coordinate, or blend into a functioning or unified whole. As applied to the aircraft and propulsion industry, integration has been used to describe several functions. For example, the process of designing physical interfaces between airframe and engine has been referred to as propulsion system integration. The same idea has been applied to control hardware where the physical relationship between fuel delivery systems, sensors, actuators and computational elements are considered in an integrated manner to facilitate efficient information exchange. Integration in the same sense can also occur in functional control design, that is, the exchange and use of information among computational elements to exploit interactions between the subsystems being controlled. In this regard, as indicated briefly in the previous section, control integration has taken place between flight, avionics, weapons, and, to a limited degree, propulsion subsystems. Integrated flight-propulsion control, then, as used within the context of this paper, is defined as the complete functional unification of information flow, on a control law basis, between force and moment effectors of the aircraft and propulsion subsystems to exploit their interactions for total system performance improvement. Levels of control system integration are depicted in figure 3 for a typical V/STOL system. On one end of the spectrum falls the use of two separate systems and on the other end a combined computer system that performs all fight and propulsion control functions. The optimum probably lies somewhere in between. There is no general body of control theory which can be applied directly to solve this problem so that design methodologies are necessary to permit the application of general theory.

In like manner, the notion of a system should be investigated. If one asked diverse people what the word "system" means, many diverse answers in each of their particular professional languages would result. When compared and reduced, however, the notion common to all of them could probably be stated as "a system is something which accomplishes an operational process." The system is an operating entity that operates upon that which is called input, to produce that which is called output. A system is therefore a device, procedure, or scheme which behaves according to some description, its function being to operate on information in a time reference to yield information. The term "system" emphasizes that an overall operational process is under consideration rather than a collection of pieces. This concept is imperative in any study of integrated control methodology and it is of utmost importance to define the flight-propulsion system.

The large degree of dynamic cross-coupling that exists between the airframe and propulsion subsystems for V/STOL alrcraft provides the main impetus for integrating flight and propulsion control systems. In powered-lift aircraft, the dynamics of the propulsion system become as important as those of the aircraft since forces and moments are generated directly or indirectly by the propulsion system on the airframe. An effective integration must optimize the favorable interactions to enhance aircraft maneuverability, flight path control, and fault tolerant systems design. The fault tolerant design aspect involves the substitution of secondary or subsidiary control functions that 
can be used to effect satisfactory control without a prime failure. For example, in a propulsive-lift concept, pitch control could be effected with aerodynamic surfaces or forward and aft thrust split between nozzles. This provides a level of redundancy and, if a failure in either one occurs, the control function would not be compromised, at least not to a catastrophic degree.

Integrated control imposes the systems approach on the traditional problem of separate flight and propulsion control by considering the aircraft as an overall system with the airframe and propulsion as subsystems. With this concept then, the propulsion system becomes, in essence, a highly sophisticated actuator acting within the framework of a flight control. Certain requirements are implied in this approach, most of which center about the reliability of the propulsion controls subsystem.

Traditionally, aircraft dynamicists tend to use a sophisticated airframe dynamic model in conjunction with a rudimentary model for the engine when analyzing the flight control system since the engine is considered to have little influence in the flight control design. This is the so-called big-airframe, little engine approach. On the other hand, propulsion system manufacturers have traditionally used the opposite approach. That is, they use the bigengine, little-or-no-aircraft analysis approach. The application of integrated control methodology will require simulations of comparable levels of detail in both the airframe and propulsion system. Integrated control methodology demands an integrated simulation approach.

\section{Operational Requirements}

V/STOL aircraft have unique operational requirements (ref. 14) in addition to those of conventional alrcraft. The propulsion requirements are summarized here from that reference as background to this paper. Among these requirements are the ability to takeoff and climb from relatively confined spaces, accomplish transition from aerodynamic lift to powered-lift and vice-versa, and to hover precisely for positioning and landing. Control in these modes are influenced not only by typical low-speed instabilities, but are complicated by forces and moments associated with thrust-induced effects, ground-effects, hot gas ingestion, and thrust effector dynamics. Providing sufficient control power to compensate for the lack of inherent stability and to counteract these various sources of disturbances usually creates a penalty because control power for low-speed operation must, in one form or another, be extracted from the propulsion system. This control power can come at considerable cost to propulsion system performance and subsequently from airframe weight which reflects on overall aircraft performance.

\section{Control Authority}

For each mode in the flight spectrum of powered-lift aircraft, the force and moment authority needed to develop the required accelerations must be defined. In hover, the entire control capability is derived from the propulsion system, either through direct thrust or bleed air from the engine compressor. This combined control in pitch, roll, yaw and trim is of major concern to the flight control designer since the combined requirement could be as high as one-fourth of the thrust-to-weight ratio needed to simply hover and 
therefore penalize the aircraft's payload and range performance. In fact, any thrust held in reserve for control will reduce mission effectiveness and could even prevent the aircraft from proceeding beyond the design phase.

Other options may be considered as a means for alleviating this substantial demand on the propulsion system for control. These include using short takeoff and prioritization of control command for each of the control axes. In the case of the latter, this means that when the aircraft is operating below maximum thrust, each individual control axis would have full authority. At maximum thrust with more than one control demanding, a proportional reduction is applied to each axis depending on the control priority. Attitude control systems which reduce bleed dependency or eliminate it completely should be the goal of any future powered-lift concept. This could be accomplished or at least abetted through use of differential thrust in the primary and augmentor thrust effector control. These effectors can include thrust vectoring-thrust reversing, split deflecting, and ventral nozzles.

One concept to exploit reduced bleed was developed in the V/STOL Controls Analysis Program (ref. 15). A concise description and discussion of this concept is also presented in reference 16. In this study, a baseline propulsion system was selected as shown in figure 4 . It consisted of a variable cycle engine (VCE) with a remote augmented lift system (RALS). Nominal primary and remote augmentor operation produces 45 percent of total engine thrust in the remote nozzle and the remaining 55 percent in the augmented deflected exhaust nozzle (ADEN). Primary and remote augmentor fuel flow modulation produces a \pm 12 percent thrust modulation capability in each nozzle, which is used in conjunction with thrust vectoring for height, pitch, and yaw control during vertical and low-speed flight operations. Only roll control is provided by compressor bleed air which is ducted to wing-tip puffer jets.

Figure 5 shows typical steady-state thrust capabilities for the system. Changes in total thrust demand are accommodated by primary changes in engine fuel flow and rotor speeds which slide the operating box to the left along a constant thrust split line. Thrust split is set by modulating the amount of bypass duct air to the remote system which slides the operating box downward along a constant total thrust line. The individual primary and remote thrust levels are varied by the flight control in response to attitude control correction demands which translates the operating point within the operating box. Transition from the vertical flight regime to horizontal flight is accomplished in a similar fashion.

In transition from wing-borne to fully propulsion-sustained flight, flight path control is usually obtained from deflected thrust and attitude pitch control. It is in this flight regime that the highest interaction between airframe and propulsion system occur. The degree of coordination between axial acceleration and flight path authority determines how quickly the aircraft can transition from wing-borne flight to powered-lift and reverse. As important here, is the use of systems to augment thrust. The major impact on propulsion systems in this flight regime is the use of systems to augment thrust. Augmentation systems add system complexity but provide alternate control force sources.

The low inherent static and dynamic stability at low airspeed, control cross-coupling, and sensitivity to disturbances are all significant influences 
on the precision of control that the pilot can achieve and the effort that must be devoted to control undesired responses. Deficiencies in the low-speed flying qualities of V/STOL aircraft require the use of the flight-control system to improve the precision of control and reduce the effort the pilot must devote to aircraft control during hover and transition.

To accomplish these higher levels of control augmentation on a V/STOL configuration, integration of the flight and propulsion control system is required. This integration could be implemented as simply as having servos drive the power and thrust vector levers within the flight control. Even in this case, the dynamic response characteristics of propulsion system elements including its thrust effectors must be considered in the fiight control design. Similarly, the forces and moments imposed on the aircraft by the propulsion system must be considered and the propulsion system treated as a primary flight control element as to rates, response, accuracy, and reliability. To achieve this level of integration, especially in view of some of the advanced V/STOL concepts, it is necessary to conduct a more systematic study of the integration of the flight and propulsion systems and to determine to what extent it is beneficial. Digital control technology and modern control design theory coupled with the current technology level of integrated design methodologies make it feasible to undertake such a design study.

\section{SUPERSONIC STOVL INTEGRATED FLIGHT-PROPULSION CONTROL PROGRAM}

Over 25 years of sporadic U.S. research and technology involvement in powered-lift including VTOL, STOL, V/STOL, and nOW, STOVL, has generated seVeral propulsion concepts. Some have been taken to flight, with some successful and others not. All current successful aircraft, however, are subsonic. The opportunity now exists to investigate the implications of supersonic flight on powered-lift vehicles. Although the integration of flight and propulsion controls must eventually be considered throughout the entire flight envelope of the vehicle, the primary concern remains in the subsonic flight phase and terminal operations. Configuring powered-lift aircraft to minimize induced lift and drag, which effect the forces and moments of the aircraft, is also a primary consideration. The major importance to STOVL in the supersonic regime, however, is configuring the alrcraft to accommodate the various propulsion concepts for minimum drag.

There are currently five supersonic STOVL propulsion concepts being considered for STOVL aircraft. Four of these concepts with typical aircraft configurations, shown in figure 6, are: ejector augmentation, deflected or vectored thrust, remote burning augmented lift, and tandem fan. The fifth is the lift-plus-cruise concept. The goal of the propulsion community is to have the enabling propulsion technologies in place to permit a low risk decision regarding the initiation of a research STOVL supersonic attack/fighter aircraft in the mid-1990's. This technology will effectively integrate, enhance, and extend the supersonic cruise, STOVL, and fighter/attack programs to enable the U.S. industry to develop a revolutionary supersonic short takeoff/vertical landing fighter/attack aircraft in the post-ATF period. The benefits include runway independence and basing flexibillty for aircraft with high survivability and maneuverability. Since the successful development of a supersonic STOVL aircraft is propulsion driven, propulsion technology issues are the key critical technologies required to achieve this goal. Within these technology 
issues, integrated flight-propulsion controls is considered one of the enabling technology which will permit demonstration of the design capability to provide viable powered-lift propulsion systems.

Integrated control technology derives primarlly from flight control requirements and other technology elements common to advanced STOVL aircraft. As discussed previously in a rather condensed form, these include control force/moment generator performance, their effect on stability and control, and integrated flight-propulsion control design methodology. It becomes necessary then, to investigate these elements in a program that will determine their relationship to aircraft performance and to aircraft handling qualities specifically. Objectives should include: (1) the evaluation of control force and moment capability of thrust effectors which may be used in STOVL propulsion configurations, (2) the evaluation of the stability and control characteristics using aerodynamic and aeropropulsion predictions, and (3) the definition of integrated flight-propulsion control concepts. The second objective is within the realm of flight dynamicists. The first and third, however, require an interdisciplinary approach with the results injected into the second objective. If integrated flight-propulsion control is a prime technology area then it follows that an integrated program approach is necessary.

On the basis of the flight control technology requirements and the strength of the V/STOL Controls Analysis and DMICS programs, a joint NASA Lewis and Ames controls program for supersonic STOVL aircraft was developed to generate the required integrated control technology and to validate its effectiveness. The overall objective of the NASA Supersonic STOVL Integrated Flight-Propulsion Control Program is to define and develop integrated control technology for achieving supersonic STOVL flight-propulsion controls integration: (1) to enable controlled transition from takeoff to forward flight to hover with reduced pilot workload, (2) to enhance aircraft handling qualities through propulsion control, (3) to extend control logic across the total flight environment, (4) to assess unique supersonic STOVL operating requirements, and (5) to refine propulsion system and control modeling for piloted simulation.

The approach will use cooperative design, simulation, and experimental facilities of aircraft and propulsion centers to jointly develop, evaluate, and validate supersonic sTovl integrated flight-propulsion concepts. Elements of this program approach include: (1) analytical modeling of non realtime and realtime models of supersonic aircraft (NASA Ames) and propulsion systems (NASA Lewis) for controls analysis and piloted simulation, (2) identification of integrated control design approaches and concepts by application of advanced and modern control methods and theories, (3) performance evaluations of control system concepts using piloted simulation on the NASA Ames Vertical Motion Simulator (VMS) and experimental system evaluations on the NASA Lewis Powered Lift Facility (PLF) including aircraft simulations to verify analysis, and (4) use of planned supersonic STOVL control effector component/engine integration tests on the PLF to determine their transient effects on aircraft force and moments and to improve modeling and control concept fidelity. Also included is propulsion support for flight evaluation. 


\section{Specific Elements}

Specific elements of the program are shown on figure 7 . These are: (1) Control Effector Dynamics, (2) Integrated Flight-Propulsion Control Concepts, and (3) Integrated Controls Methodology. An additional planned element is Flight Program Propulsion Control Support. A brief discussion of each element follows.

\section{Control Effector Dynamics}

The Controls Effector Dynamics element is basically an in-house program to determine the transient and dynamic performance of thrust effectors unique to STOVL. These effectors include ejector augmentors, remote and fan flow burners, and vectoring, reversing and ventral nozzles. Associated flow switching valves and bleed-flow extraction are also of interest and are being obtained in joint efforts with the Air Force. Propulsion induced effects created by these thrust effectors have a primary impact on aircraft stability and control and form an important link to integrated control design. Objectives include the definition of (1) force/moment envelopes in takeoff, transition and hover modes, (2) thrust modulation/deflection capability, and (3) reaction control demand effects on bleed requirements and engine performance. The approach is to first determine which data are available to define the effector performance and then to execute tests if necessary. Data such as startup transients, modulation ability and range, flow deflection ability and frequency response will be sought. The primary product of these investigations will be verified simulation models which can be used in systems and controls analyses and overall systems evaluations. The forces and moments produced from the effectors and their propulsion induced effects on the aircraft will be determined in wind tunnel programs.

Thus far, a simulation modeling effort has been initiated and a transient performance test on a full scale ejector planned. The test is part of the U.S.-Canada Focused Ejector program which has been on-going for the last few years. A more complete description of that program will be presented later. Concern with ejector augmentation from a controls viewpoint lies primarily with its start-up transient characteristics and its ability to deflect or vector thrust.

An investigation into the remote burner augmentation concept is currently underway. At this point it appears that transient characteristics are sufficiently defined. The major unknown in this augmentor concept is its propulsion induced effects on the aircraft which must be determined to evaluate its effects on the transition envelope and stability requirements before realistic integrated control studies can proceed.

\section{Integrated Flight-Propulsion Control Concepts}

The issues involved in this element revolve about the technology validation of integrated control concepts while stressing the generic aspects of its technology. In the validation issue, advantage must be taken of existing technology programs while applying current methodologies such as DMICS in the controls discipline with the goal of extending and validating integrated control 
technology. The generic issues include system complexity and design methodology. It is this last issue which is of most importance to the program element. The approach to satisfying these issues was to take advantage of concepts of opportunity by considering existing databases, status of simulations, propulsion system availability, existing experimental programs, overall system complexity, and the application to a possible flight program. The U.S.-Canada Focused Ejector program provides one concept of opportunity. It should be stressed here that the augmented ejector propulsion concept may not be the concept of choice for further specific development and that it is being used only as a means to accomplish an integrated controls application. In fact, any particular concept has only a minor effect on the development of integrated controls. Since controls are historically systems oriented, issues such as system complexity, multivariable and interactive character, design methodology and broadness of methodology applicability are the major items of interest and the ejector augmentor concept meets these criteria.

The U.S.-Canadian Focused Ejector Program is an on-going program between these governments to validate the technology and evaluate a viable ejectoraugmented powered-1ift propulsion system for supersonic STOVL alrcraft at full-scale. The program involves DeHavilland, General Dynamics and General Electric as contractors. Prior research has shown that adequate ejector thrust performance can be achieved but that efficient movement of primary air from the engine to the ejector is absolutely necessary for concept success. From a propulsion viewpoint, the approach used in the program is to design, fabricate, test and evaluate a fan air collector, valving, ducting, and ejector system which meets the performance requirements of an ejector augmented supersonic STOVL aircraft using the latest analyses and experimental results from component tests. Large-scale experimental evaluations involve, specifically, the General Dynamics E-7D aircraft design and a General Electric F110 engine with DeHavilland ejectors. The large-scale aircraft model and propulsion system will be evaluated on the NASA Lewis Powered Lift Facility (PLF) and the NASA Ames $40 \times 80$ wind tunnel. The program forms a unique research capability on which to conduct integrated controls research.

The Integrated Controls Research Demonstrator becomes, then, an integrated adjunct to the on-going program to the extent that it does not duplicate common efforts. Its object is to develop and validate the application of an integrated flight-propulsion control design methodology. The program is depicted in figure 8. Using aircraft model data, a simulation of the aircraft and propulsion system will be generated for use in integrated controls analysis and evaluation. The aircraft model and propulsion system hardware including controls will be mounted on the NASA Lewis PLF. Aircraft dynamics and the flight control segment of the integrated control will be simulated on the NASA Lewis Controls and Simulation Laboratory which consists of two Applied Dynamics International (ADI) System 100 digital computers. System evaluation will be accomplished by using a simulation of a human pilot to fly the aircraft through prescribed flight exercises. Subsequent to this experimental program, a final phase of evaluation will include the testing of the E-7D on a static test stand and the 40 - by 80 -Foot Wind Tunnel at NASA Ames and an integrated control evaluation for handling qualities on the NASA Ames Vertical Motion Simulator (VMS).

Another program within the integrated flight-propulsion control concept element, as shown on figure 9 , is a DMICS-type design application to a 
vectored thrust configured aircraft. The objectives here are to not only reveal integrated control related problems, but to provide an alternative concept for integrated flight-propulsion control design methodology validation and subsequently determine if the design methodology is configuration dependent. The program consists of a definition of system requirements, simulation development, generation of integrated control laws for a hybrid vectored thrust configuration including fault tolerance logic, and a piloted flight simulation evaluation. The program may eventually be extended to include advanced control hardware with bench test and an iron-bird experimental evaluation in a collaborative program with the Air Force.

\section{Integrated Control Methodology}

The Integrated Control Methodology element is an in-house program to establish and investigate, both analytically and experimentally, alternate integrated fiight-propulsion control design methodologies. In DMICS, two design approaches were taken in the dual-award effort, one by each of the two teams on separate system designs. The first was a global approach wherein all input-output relationships were defined from an integrated linear system. The integrated control was synthesized using a reduced-order 1 inear model by applying a Linear-Quadratic-Gaussian (LQG) Loop Transfer Recovery (LTR) technique in a centralized approach. The other study used a hierarchical decentralized LQG approach with multi-objective optimization. A basic philosophy of this design approach is that subsystem partitioning is not assumed prior to analysis but is an output of the design process. The design starts out as a centralized process in a high-level design and the results used to establish a decentralized control design followed by overall system optimization. The decentralized system reduces the control complexity by distributing control authority to local controllers which attempt to meet only part of the overall performance requirements.

Although both methodologies resulted in a kind of design manual for integrated control, it is still undetermined if a different methodology applied to the same operational system would produce the same, different or better results. An effort to examine alternate methodologies on the same system would appear in order. While one of the objects in the Integrated Flight-Propulsion Concept element described earlier is the application and evaluation of a DMICS-type design methodology to different propulsion concepts, the object of the Integrated Control Methodology element is to examine alternative design methodologies on the same system. Current alternatives for integrated control design methodology include: (1) a centralized multi-objective optimization technique, and (2) an optimized introduction of cross-feeds process. Conceptual flow paths for these processes are shown in figure 10. These alternative processes flow from common sense permutations of the DMICS methodologies. For example, the first alternative combines the centralized approach of the DMICS global methodology with the partitioned feature of the other DMICS design process.

In the execution of this research element, design methodologies will be applied to the ejector augmented configuration used in the previously described research demonstrator program. An integrated control will be designed and evaluated experimentally in the same manner as in that element except that a pilot station with real pilots may be used in a ground-based preliminary 
evaluation prior to a moving-base piloted simulation evaluation on the NASA Ames VMS. In addition, the opportunity will be taken to apply advanced fault tolerant concepts.

\section{CONCLUDING REMARKS}

The primary problem in developing propulsion system concepts is to design systems which provide the required aircraft handling qualities in powered-lift modes without robbing the powerplant of its ability to perform safely and economically. During low speed operations V/STOL aircraft are not only dependent upon its propulsion system for lift, but also for the forces and moments needed for flight path and attitude control. Thus, highly coordinated flight and propulsion control systems are critical to the success of these advanced V/STOL aircraft.

The large degree of dynamic cross-coupling that exists between the airframe and propulsion subsystems for V/STOL aircraft provides the main impetus for integrating flight and propulsion control systems. In powered-lift aircraft, the dynamics of the propulsion system become as important as those of the aircraft since forces and moments are generated directly or indirectly by the propulsion system on the airframe. Control authority requirements place significant demands on the propulsion system. An effective integration must optimize the favorable interactions to enhance aircraft maneuverability and flight path control. The potential payoff in mission payload without the sacrifice of control authority or propulsion system reliability is worth investigating.

To achieve this level of integration, especially in view of some of the advanced V/STOL concepts, it is necessary to conduct a more systematic study of the integration of the flight and propulsion systems and to determine to what extent it is beneficial. Digital control technology and modern control design theory coupled with the current technology level of integrated design methodologies make it feasible to undertake such a design study.

On the basis of the flight control technology requirements and the strength of previous programs, a joint NASA Lewis and Ames controls program for supersonic STOVL aircraft has been developed to generate the required integrated control technology and to validate its effectiveness. The overall objective of the NASA Supersonic STOVL Integrated Flight-Propulsion Control Program is to define and develop integrated control technology for achieving supersonic STOVL flight-propulsion controls integration.

\section{ACKNOWLEDGMENTS}

The author wishes to express his appreciation to Dr. James A. Franklin, NASA Ames Research Center, for his contributions to the flight requirements section of this paper, and to Dr. Bruce Lehtinen, NASA Lewis Research Center, for his contribution and comments on alternative integrated control

methodologies. 


\section{REFERENCES}

1. F.W. Burcham Jr. and P.G. Batterton, "Flight Experience With a Digital Integrated Propulsion Control System on an F-111E Airplane," AIAA Paper 76-653, July 1976.

2. A.W. Nieuwenhuijse and J.A. Franklin, "A Simulator Investigation of Engine Failure Compensation for Powered Lift STOL Aircraft," NASA TM X-62363, 1974.

3. J.R. Mihaloew and C.E. Hart, "Real Time Digital Propulsion System Simulation For Manned Flight Simulators," NASA TM-78958, 1978.

4. E. Rachovitsky, "Opportunities in Flight/Propulsion Control Coupling (FPCC)," SAE Paper 740482, Apr. 1974.

5. R.L. Heimbold, J.A. Hauge, and R.J. Miller, "Flight Propulsion Control Coupling (FPCC) and Dynamic Interaction Investigation," AFFDL-TR-75-153, Air Force Flight Dynamics Laboratory, Wright-Patterson AFB, OH, Sept. 1975.

6. R.J. Miller, L.D. Emerson Jr., R.L. Heimbold, and J.A. Hauge, "Control Configured Propulsion (CCP) Design Criteria Definition," AFFDL-TR-76-33-VOL-1, Air Force Flight Dynamics Laboratory, Wright-Patterson AFB, OH, July 1976.

7. D.L. Anderson, et al, "YF-12 Cooperative Airframe/Propulsion Control System Program," NASA CR-163099, 1980.

8. F.W. Burcham Jr. and J.F. Stewart, "The Development Process for Integrated Propulsion-Flight Controls," Tactical Aircraft Research and Technology, Vol. 1, NASA CP-2162, 1980, pp. 123-140.

9. "V/STOL Propulsion Control Analysis - Phase II Final Report," NASA CR-165523, 1981 .

10. W.B. Kerr, S.P. Roth, R.J. Miller, and R.E. Creekmore, "V/STOL Propulsion Control Analysis - Phase II Final Report," NASA CR-165522, 1981.

11. K.L. Smith, W.B. Kerr, and G.L. Hartmann, "Design Methods for Integrated Control Systems," AFWAL-TR-84-2088, Apr. 1984.

12. D.S. Joshi, P.D. Shaw, S.M. Rock, and W.S.C. Fisk, "Design Methods for Integrated Control Systems," AFWAL-TR-84-2037, Feb. 1985.

13. W.A. Yonke, "Integrated Flight/Propulsion Control: HIDEC Modes, " NAECON 1984, Vol. 1, IEEE, New York, 1984, pp. 472-478.

14. J.A. Franklin, "Control of V/STOL Aircraft," Aeronautical Journal, Vol. 90, May 1986, pp. 157-173.

15. "V/STOL Propulsion Control Analysis - Phase I Final Report, " NASA CR-165207, 1980.

16. H. Brown, "V/STOL Propulsion Control Technology," Journal of Guidance, Control, and Dynamics, Vol. 7, Mar.-Apr. 1984, pp. 183-189. 


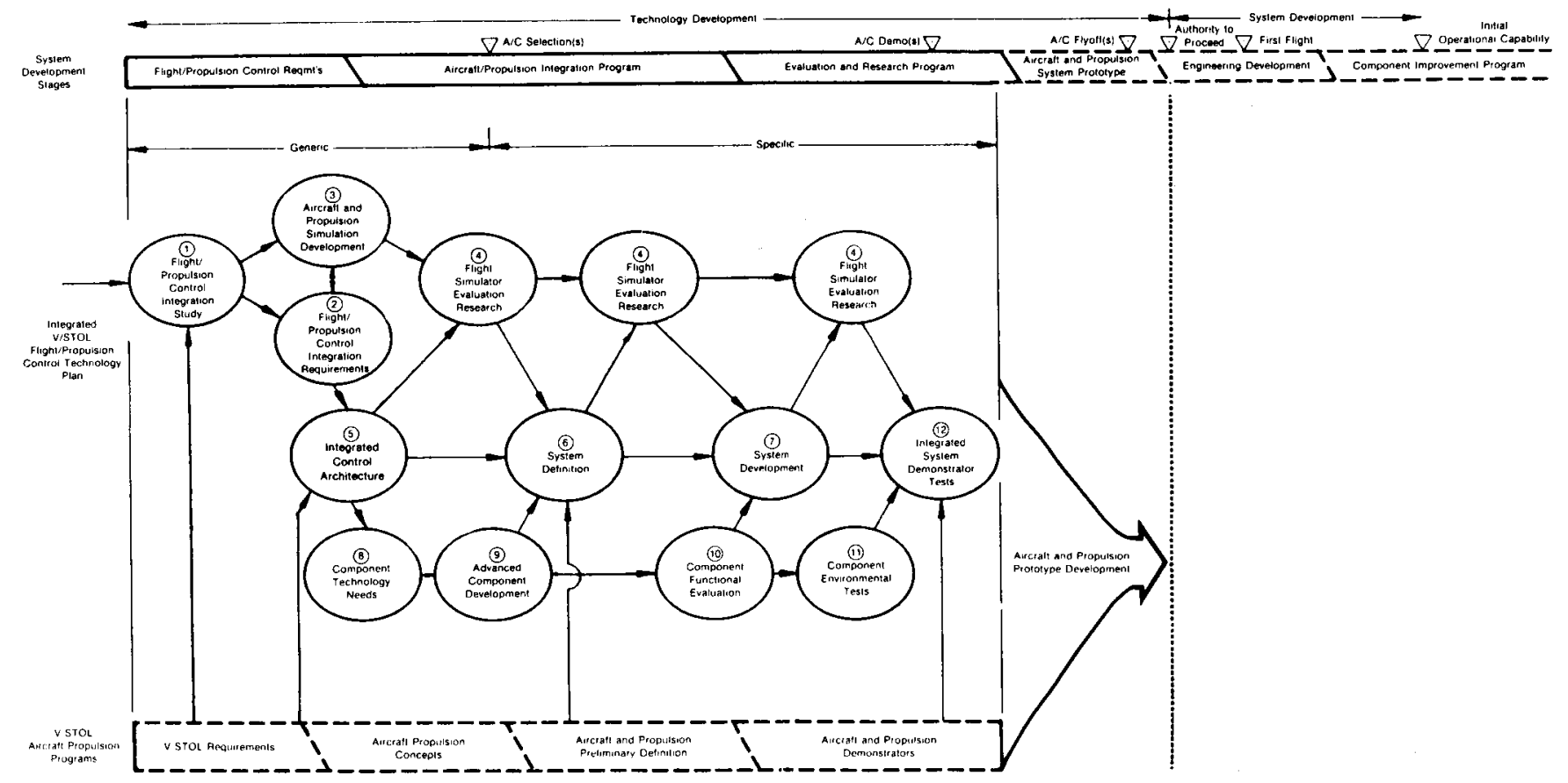

FIGURE 1. - INTEGRATED V/STOL. FLIGHT/PROPILLSION CONTROL TECHNOLOGY DEVELOPMENT PLAN.

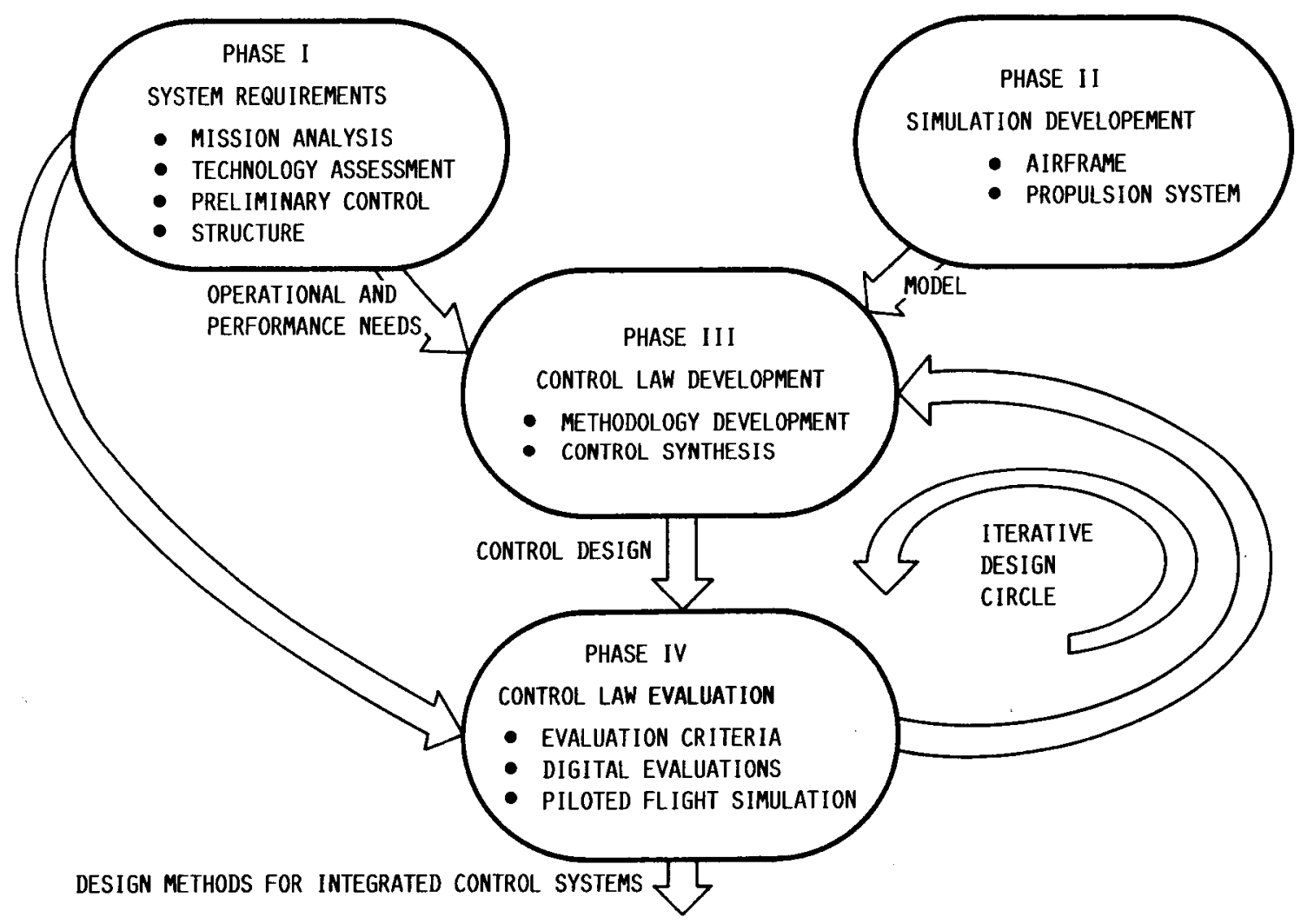

FIGURE 2. - DMICS PROGRAM PHASES. 


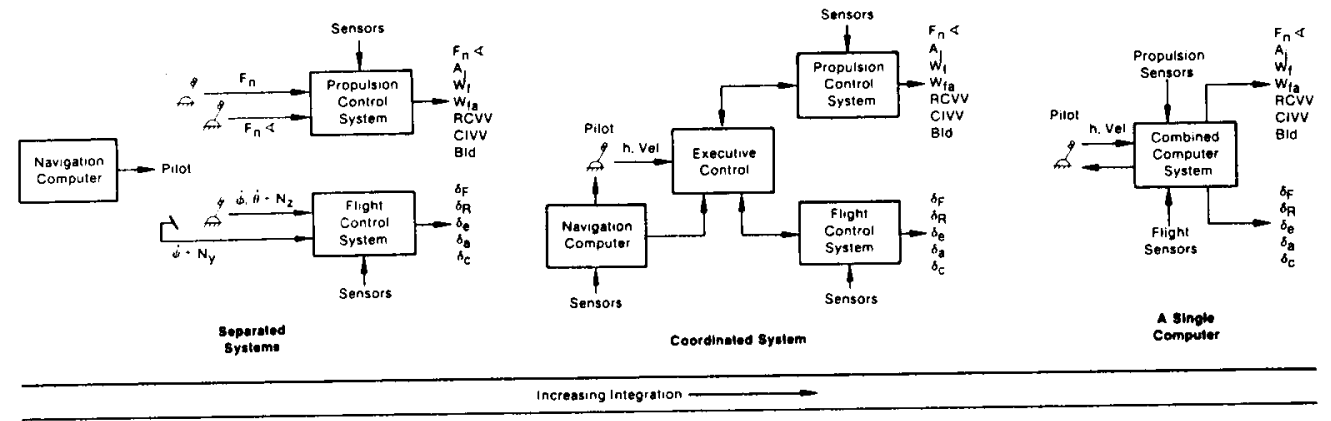

FIGURE 3. - LEVELS OF V/STOL CONTROL SYSTEM INTEGRATION.

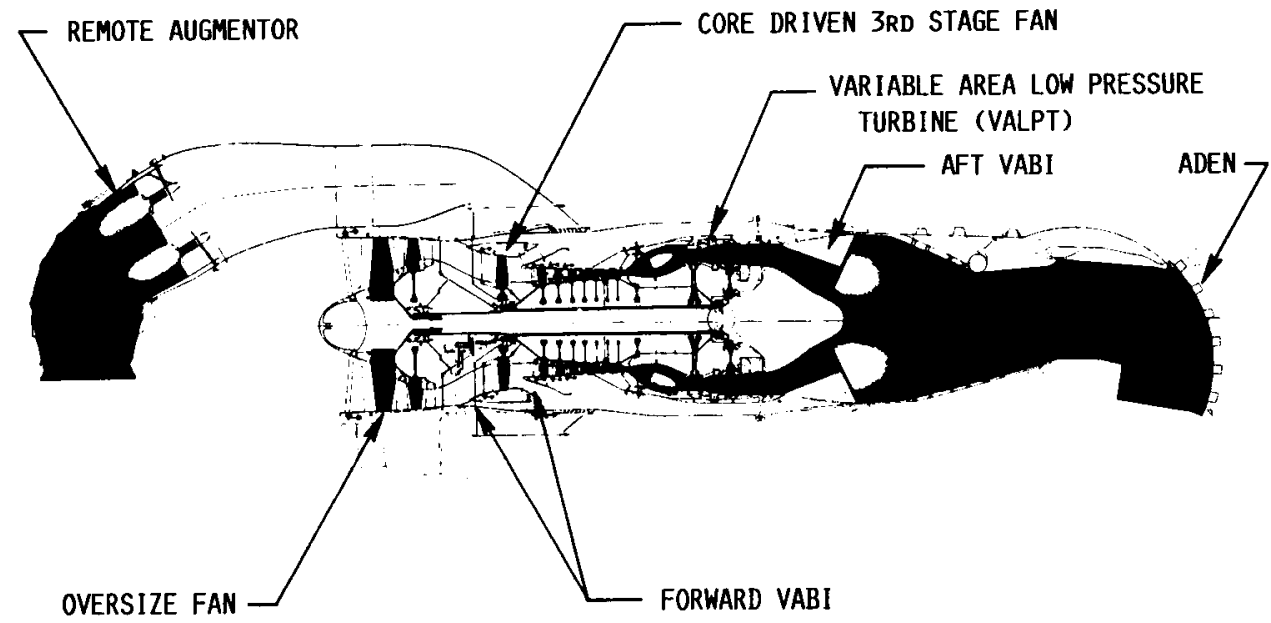

FIGURE 4.- VCE/RALS BASELINE ENGINE.

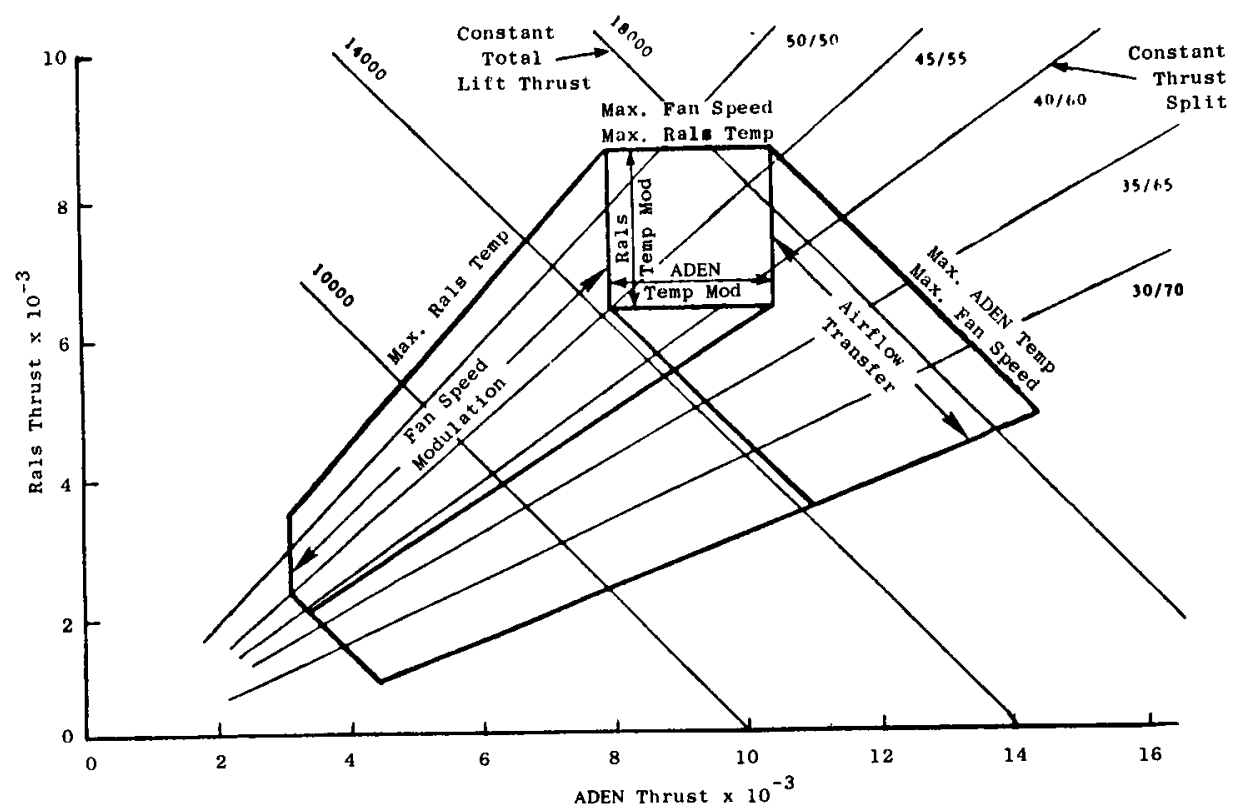

FIGURE 5. - RALS THRUST MODULATION VTOL MODE. 
ORIGINAL PAGE IS

OF POOR QUALITY
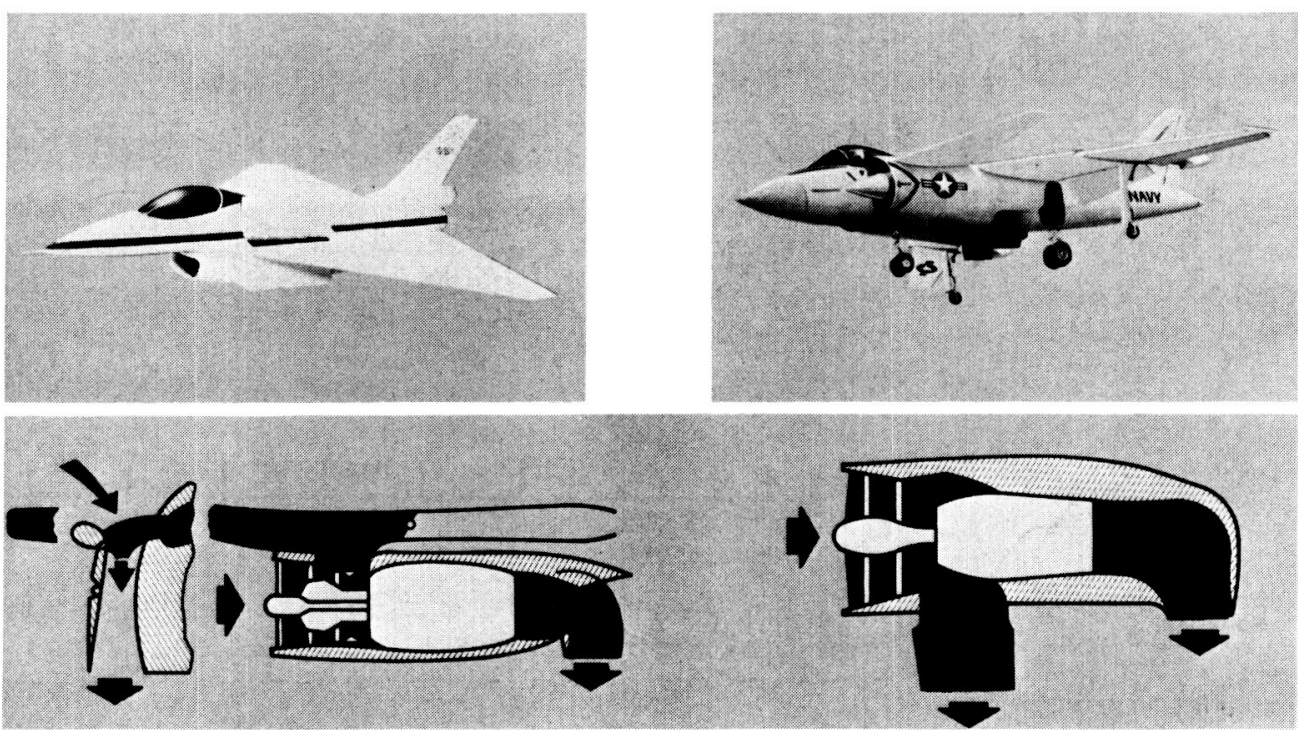

EJECTOR SYSTEM

DEFLECTED THRUST SYSTEM

FIGURE 6. - SUPERSONIC V/STOL PROPULSION SYSTEMS.
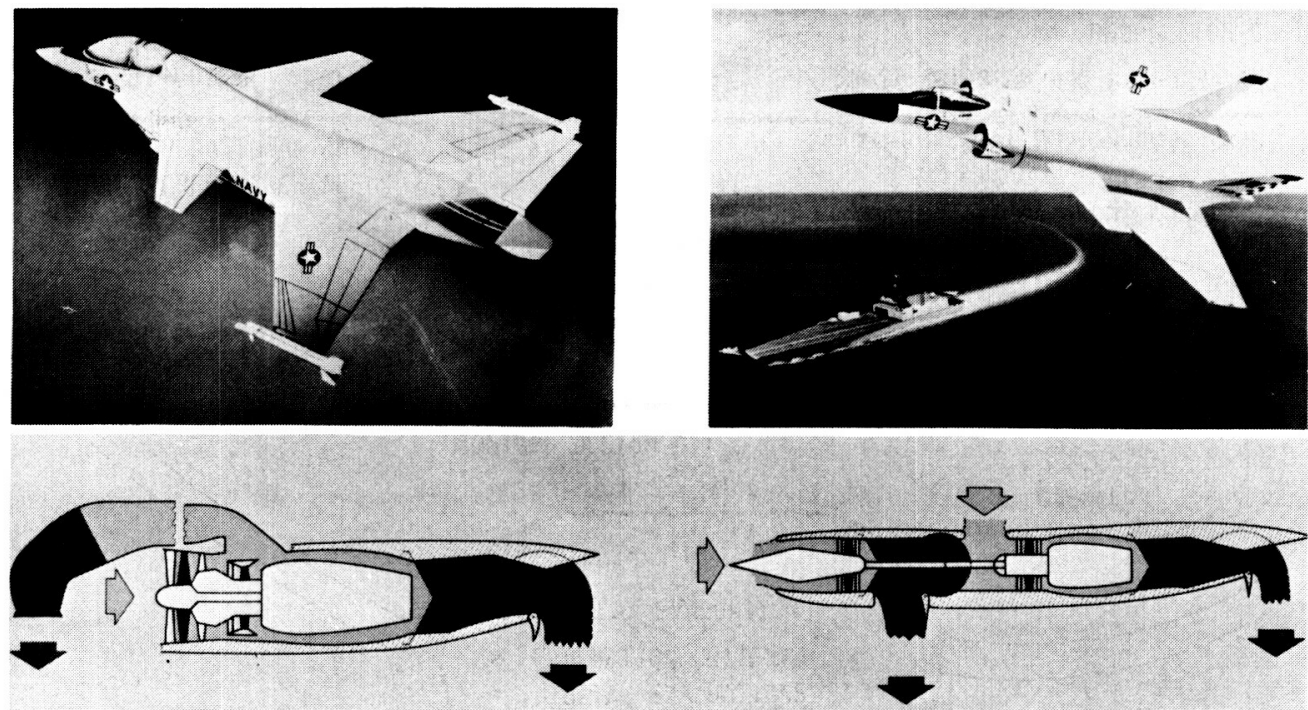

REMOTE AUGMENTED LIFT SYSTEM

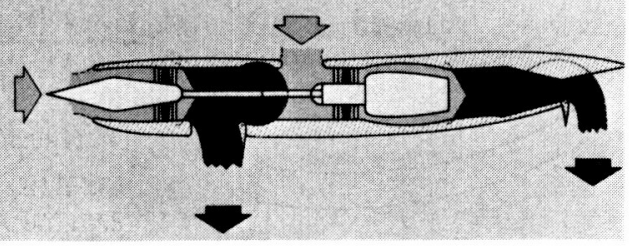

TANDEM FAN SYSTEM

FIGURE 6. - CONCLUDED. 
FISCAL YEAR ELEMENT

CONTROL EFFECTOR DYNAMICS (LERC) EJECTOR, BLEED, RALS, PCB

INTEGRATED FLIGHT-PROPULSION

CONTROL CONCEPTS (LERC/ARC)

AUGMENTED EJECTOR (GE)

VECTORED THRUST (PWA)

REMOTE LIFT (GE/USAF)

INTEGRATED CONTROLS METHODOLOGY (LERC)

SIMULATION EVALUATION (LERC)

\begin{tabular}{|l|l|l|l|l|l|l|l|}
87 & 88 & 89 & 90 & 91 & 92 & 93 & 94 \\
\hline
\end{tabular}
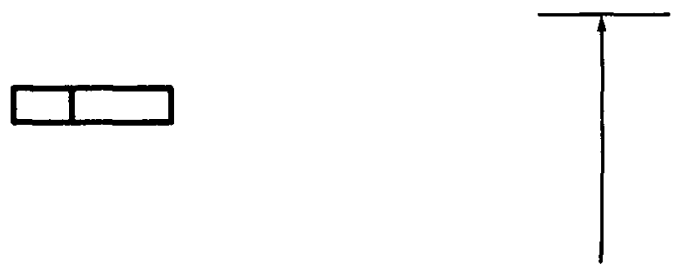

TECHNOLOGY DEVELOPMENT
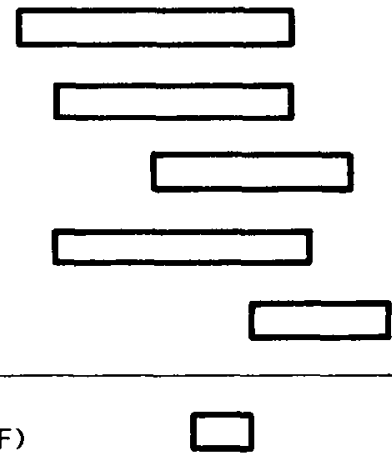

CONTROLS RESEARCH DEMONSTRATOR (LERC PLF)

WIND TUNNEL EVALUATION (ARC 40x80)

PILOTED SIMULATION EVALUATION (ARC VMS)

FLIGHT TEST DEMONSTRATION
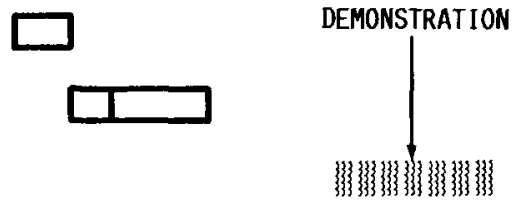

FIGURE 7. - ADVANCED SUPERSONIC STOVL CONTROLS PROGRAM. 


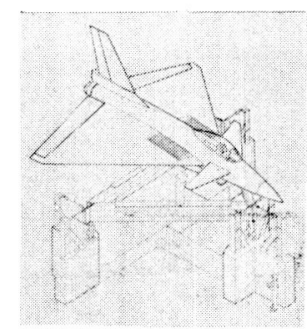

ENGINE SYSTEM/CONTROLS

MATHEMATICAL MODELING

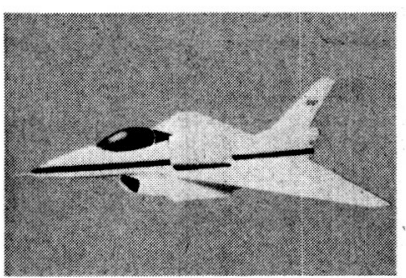

AIRCRAFT - NASA AMES

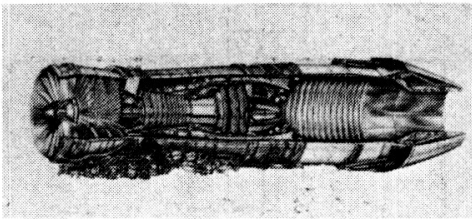

PROPULSION - NASA LEWIS
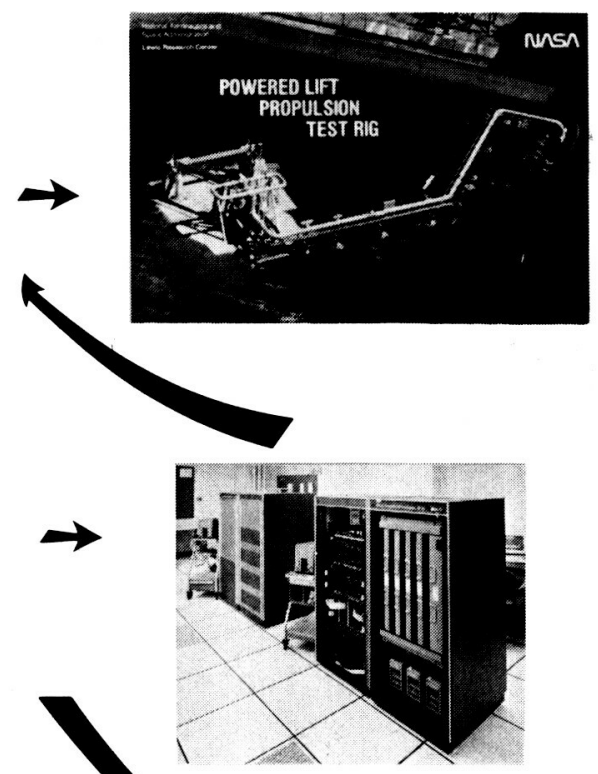

FIGURE 8. - INTEGRATED CONTROLS RESEARCH DEMONSTRATOR PROGRAM.

INTEGRATED SIMULATION

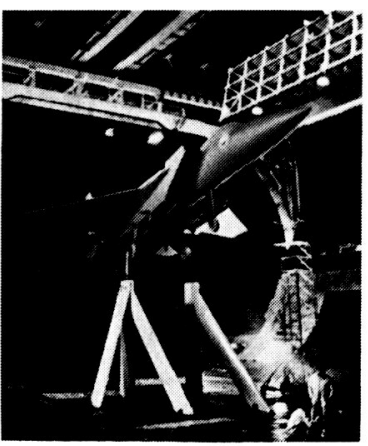

AMES 40X80 FT WIND TUNNEL

aEROdynamic
Data

PILOTED SIMULATION

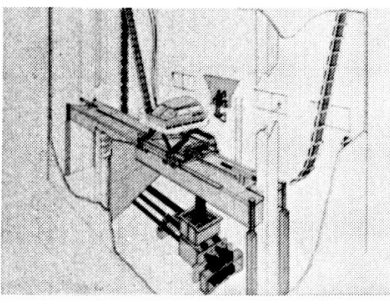

VERTICAL MOTION SIMULATOR NASA AMES

MATHEMATICAL MODEL ING
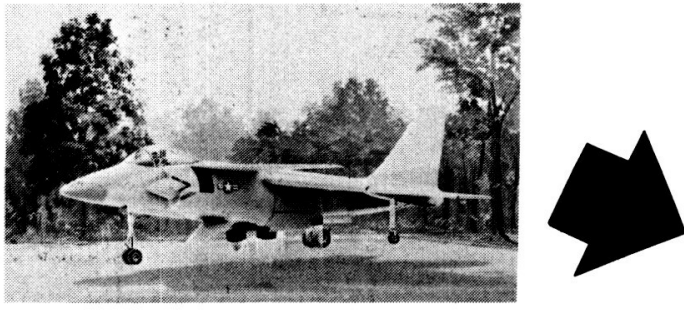

PILOTED SIMULATION

AIRCRAFT - NASA AMES
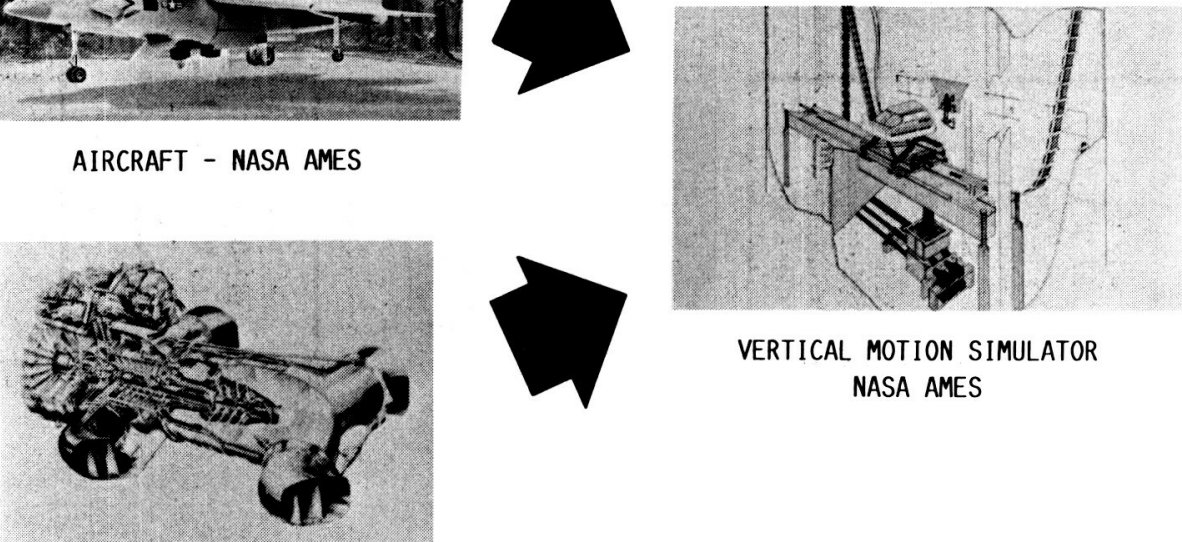

VERTICAL MOTION SIMULATOR NASA AMES

PROPULSION - NASA LEWIS

FIGURE 9. - STOVL INTEGRATED CONTROL CONCEPT RESEARCH. 

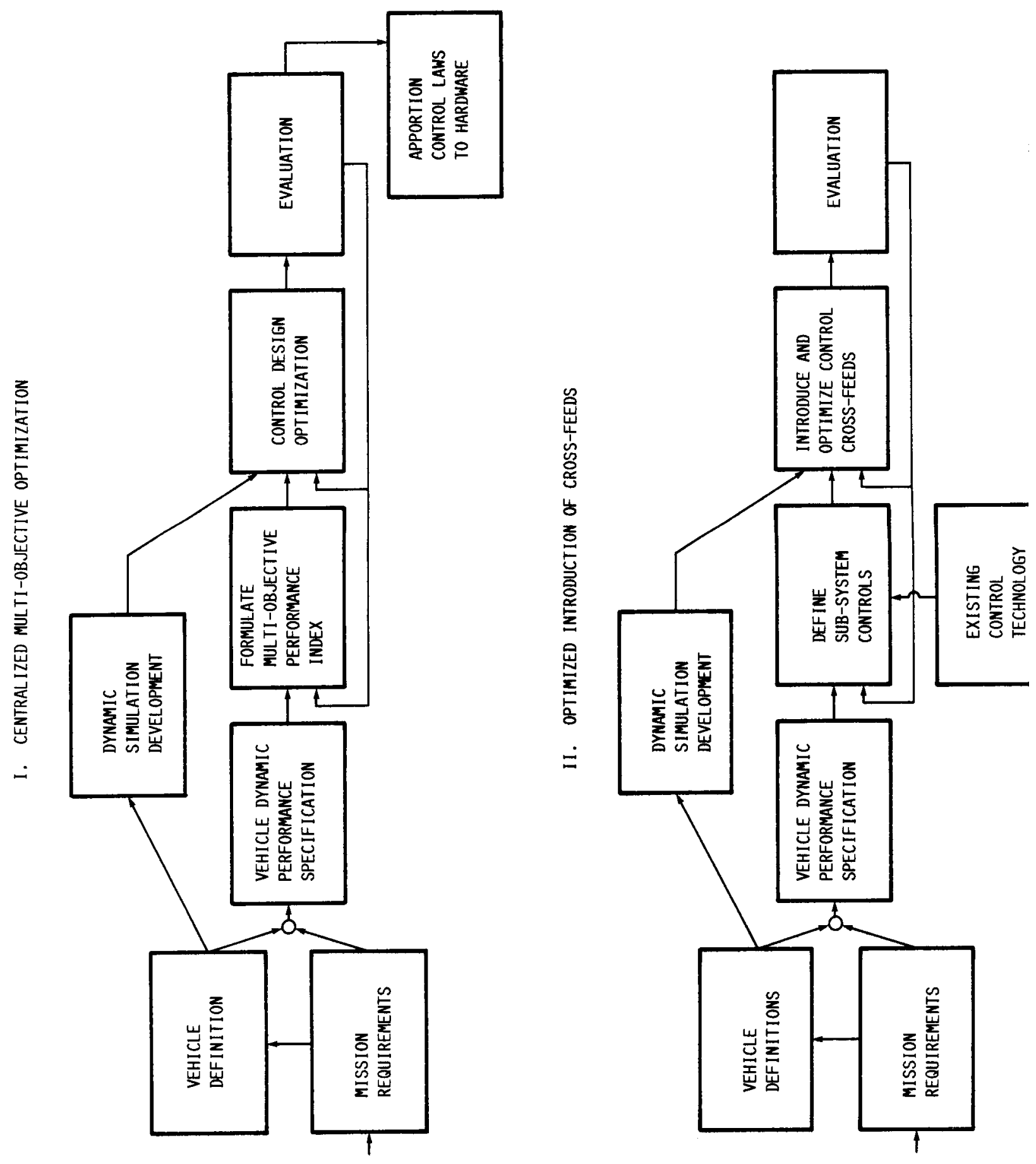


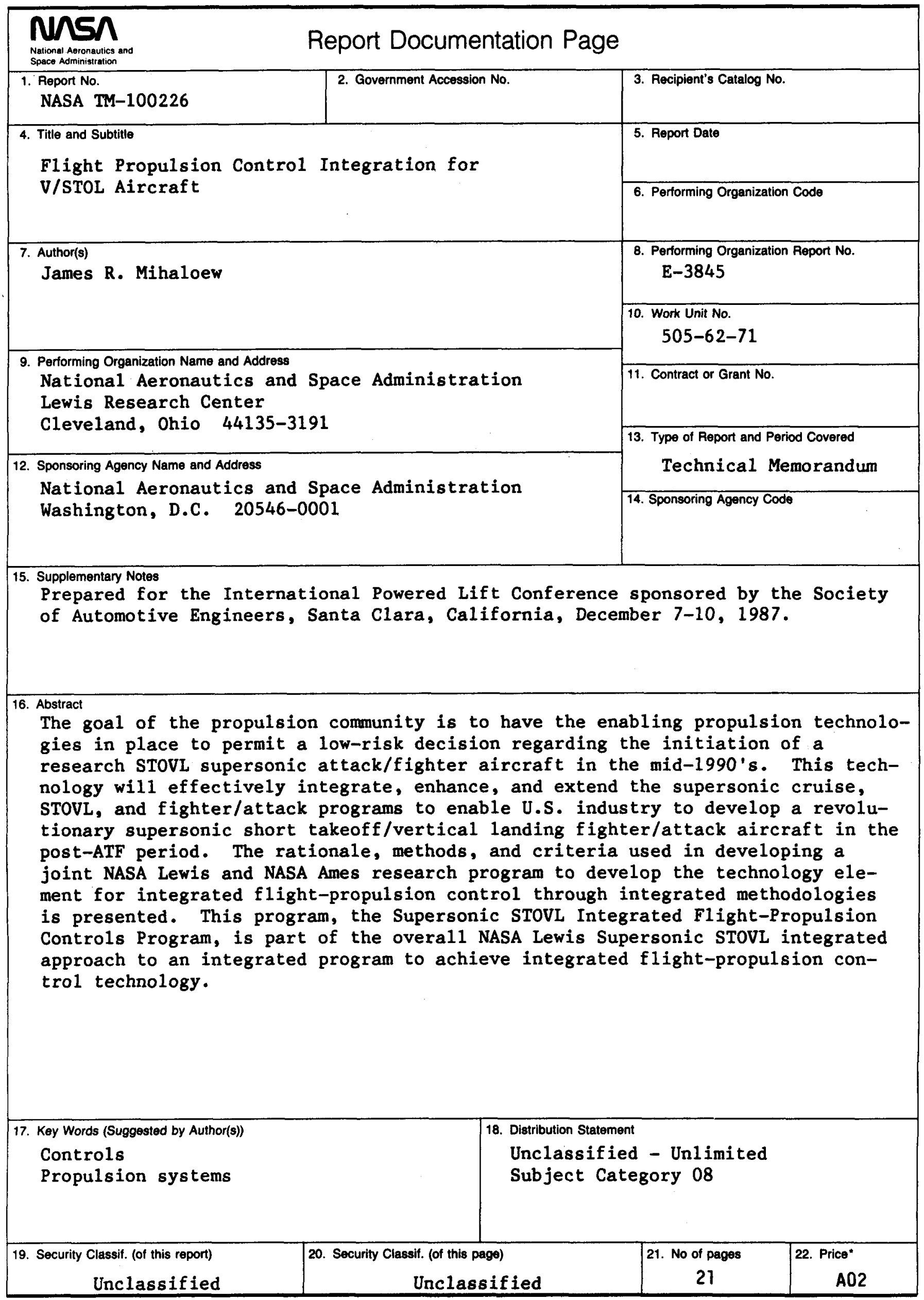

